\title{
A double-blind randomised controlled trial of protein supplementation to enhance exercise capacity in COPD during pulmonary rehabilitation: a pilot study
}

\author{
Abdulelah M. Aldhahir (10 ${ }^{1,2}$, Yousef S. Aldabayan ${ }^{1,3}$, Jaber S. Alqahtani (10) ${ }^{1,4}$, \\ Heidi A. Ridsdale ${ }^{5}$, Colette Smith ${ }^{6}$, John R. Hurst (ib) $1,7,8$ and Swapna Mandal ${ }^{1,7,8}$
}

\section{ABSTRACT}

Background: Pulmonary rehabilitation is a cost-effective management strategy in chronic obstructive pulmonary disease (COPD) which improves exercise performance and health-related quality of life. Nutritional supplementation may counter malnutrition and enhance pulmonary rehabilitation outcomes but rigorous evidence is absent. We aimed to investigate the effect of high-protein supplementation (Fortisip Compact Protein (FCP)) during pulmonary rehabilitation on exercise capacity.

Methods: This was a double-blind randomised controlled trial comparing FCP (intervention) with PreOp (a carbohydrate control supplement) in COPD patients participating in a pulmonary rehabilitation programme. Participants consumed the supplement twice a day during pulmonary rehabilitation and attended twice-weekly pulmonary rehabilitation sessions, with pre- and post-pulmonary rehabilitation measurements, including the incremental shuttle walk test (ISWT) distance at 6 weeks as the primary outcome. Participants' experience using supplements was assessed.

Results: 68 patients were recruited (intervention $n=36$ and control $n=32$ ). The trial was stopped early due to the COVID-19 pandemic. Although statistical significance was not reached, there was the suggestion of a clinically meaningful difference in the ISWT distance at 6 weeks favouring the intervention group (intervention $342 \pm 149 \mathrm{~m}(\mathrm{n}=22)$ versus control $305 \pm 148 \mathrm{~m}(\mathrm{n}=22) ; \mathrm{p}=0.1)$. Individuals who achieved an improvement in the ISWT had a larger mid-thigh circumference at baseline (responders $62 \pm 4 \mathrm{~cm}$ versus nonresponders $55 \pm 6 \mathrm{~cm} ; \mathrm{p}=0.006) .79 \%$ of the patients were satisfied with the taste and $43 \%$ would continue taking the FCP.

Conclusions: Although the data did not demonstrate a statistically significant difference in the ISWT, high-protein supplementation in COPD during pulmonary rehabilitation may result in a clinically meaningful improvement in exercise capacity and was acceptable to patients. Large, adequately powered studies are justified.

@ERSpublications

High-protein supplementation combined with pulmonary rehabilitation in COPD did not statistically improve exercise capacity but may be associated with a clinically meaningful improvement. Larger trials are needed to confirm this. https://bit.ly/3tMtX9O

Cite this article as: Aldhahir AM, Aldabayan YS, Alqahtani JS, et al. A double-blind randomised controlled trial of protein supplementation to enhance exercise capacity in COPD during pulmonary rehabilitation: a pilot study. ERJ Open Res 2021; 7: 00077-2021 [https://doi.org/10.1183/ 23120541.00077-2021].

This article has supplementary material available from openres.ersjournals.com.

This study is registered at ClinicalTrials.gov with identifier number NCT04027413. Data sharing: Participants' data, the trial protocol and the statistical plan are available upon reasonable request from the corresponding author.

Received: 29 Jan 2021 | Accepted: 1 Feb 2021

Copyright $\odot$ The authors 2021. This version is distributed under the terms of the Creative Commons Attribution NonCommercial Licence 4.0. For commercial reproduction rights and permissions contact permissions@ersnet.org 


\section{Introduction}

Patients with chronic obstructive pulmonary disease (COPD) often have daily symptoms and reduced exercise capacity, both of which result in an impaired health-related quality of life (HRQoL) [1, 2]. COPD patients may lose skeletal muscle mass, which leads to muscle weakness, dysfunction and disuse, thus negatively affecting activity, mobility and overall strength $[3,4]$. Muscle disuse can result from a sedentary lifestyle such that voluntary immobilisation leads to further muscle deconditioning and reduced muscle strength/endurance [4]. Pulmonary rehabilitation is a multiprofessional education and exercise programme that is a fundamental management strategy in COPD, resulting in improved exercise performance and HRQoL, promoting self-dependency in relation to activities of daily living while reducing dyspnoea and the risk of exacerbation [5,6]. Maximising the value and response to pulmonary rehabilitation is of great interest to clinicians and patients alike.

Malnutrition is common in COPD, and may adversely affect the ability to undertake and maximally benefit from pulmonary rehabilitation. Several studies, summarised in a recent systematic review by AlDHAHIR et al. [7], have investigated the benefit of using nutritional supplementation during pulmonary rehabilitation, but yielded conflicting results with diversity in supplements, study design and outcome measures. There is a clear need for further research. In particular, COPD patients may require a higher intake of protein, as recommended by the British Association for Parenteral and Enteral Nutrition, due to a higher protein requirement to preserve lean mass [8].

An integrated approach of exercise training and nutritional support may offer the greatest potential benefit. We hypothesised that a low-volume, high-protein oral nutritional supplement taken by COPD patients over the course of pulmonary rehabilitation would enhance benefits in terms of exercise capacity.

\section{Material and methods}

\section{Trial design}

This double-blind, parallel group randomised control superiority trial was registered at ClinicalTrials.gov with identifier number NCT04027413. The study was approved by a local ethics committee and the UK Health Research Authority (approval 18/LO/1842).

\section{Participants}

Participants with confirmed COPD (post-bronchodilator forced expiratory volume in $1 \mathrm{~s}\left(\mathrm{FEV}_{1}\right) /$ forced vital capacity $(\mathrm{FVC})$ ratio $<0.7)$ and an appropriate exposure history, enrolling on a pulmonary rehabilitation programme, were recruited from the Central and North West London NHS Foundation Trust (London, UK) between 7 January 2019 and 31 January 2020, with the last visit for the last participant completed on 20 March 2020. At this point the study had to be suspended; a national "lockdown" for the COVID-19 pandemic meant that the pulmonary rehabilitation service was stopped.

Before starting pulmonary rehabilitation, all participants were required to attend an assessment visit conducted by physiotherapists. The physiotherapist approached participants regarding the study. Patients who agreed to participate were consented and enrolled into the study by the researcher (A.M.A.). A full medical history with demographic information was collected.

Patients with any physical or mental health disorders preventing compliance with the trial protocol, or those unable to communicate in English, with malabsorption syndrome, who were unable to perform the incremental shuttle walk test (ISWT), who were already using other oral dietary supplements under the care of a dietician, had galactosaemia, had cow's milk protein allergy or lactose intolerance, or who had a body mass index (BMI) $>30 \mathrm{~kg} \cdot \mathrm{m}^{-2}$ without recent weight loss of $>5 \%$ were excluded from the study.

\section{Randomising and blinding}

Participants were randomised (1:1) using a web-based service (Sealed Envelope; www.sealedenvelope.com) with equal allocation concealment, block size 4 , stratified based on BMI $\geqslant 20$ or $<20 \mathrm{~kg} \cdot \mathrm{m}^{-2}$, given that oral nutritional supplementation is recommended in COPD patients with a BMI $<20 \mathrm{~kg} \cdot \mathrm{m}^{-2}$ or those who

Affiliations: ${ }^{1} \mathrm{UCL}$ Respiratory, Royal Free Campus, University College London, London, UK. ${ }^{2}$ Respiratory Therapy Dept, Faculty of Applied Medical Sciences, Jazan University, Jazan, Saudi Arabia. ${ }^{3}$ Respiratory Care Dept, College of Applied Medical Sciences, King Faisal University, Al-Hasa, Saudi Arabia. ${ }^{4}$ Dept of Respiratory Care, Prince Sultan Military College of Health Sciences, Dammam, Saudi Arabia. ${ }^{5}$ Central and North West London NHS Foundation Trust, London, UK. ${ }^{6}$ Research Dept of Infection and Population Health, University College London, London, UK. ${ }^{7}$ Royal Free London NHS Foundation Trust, London, UK. ${ }^{8}$ These authors contributed equally to this work.

Correspondence: John R. Hurst, UCL Respiratory, University College London, Rowland Hill Street, London, WC1E 6BT, UK. E-mail: j.hurstaucl.ac.uk 
are at medium to high risk of malnutrition. Patients were randomly assigned to the intervention or control group. The randomisation process was conducted by a member of the research team not involved in the study, before baseline assessment and following the screening visit. Both the outcome assessor and the participants were blinded to treatment allocation.

\section{Intervention and control products}

Intervention and control products were unlabelled and delivered directly to the participants' residential addresses with both researcher and participants being blinded.

The intervention was a $125 \mathrm{~mL}$ bottle of Fortisip Compact Protein (FCP; Nutricia, Zoetermeer, The Netherlands) that has $300 \mathrm{kcal}, 24 \%$ protein, $41 \%$ carbohydrate and $35 \%$ fat. The control was a $200 \mathrm{~mL}$ bottle of PreOp (Nutricia) that has $100 \mathrm{kcal}$ and $100 \%$ carbohydrate. Participants were instructed to consume two bottles each day: one bottle in the morning after breakfast prior to attending the pulmonary rehabilitation session and one bottle during the day after a meal.

Both the intervention and control products were used throughout the 6-week duration of the pulmonary rehabilitation programme.

\section{Study conduct}

All baseline measurements were conducted prior to starting pulmonary rehabilitation, these included ISWT distance, body composition, anthropometric measurements, handgrip strength and five-repetition sit-to-stand test (STS5) time. Additionally, participants were given a pedometer and instructions on its use and how to complete the supplement and step count diaries. Participants were required to complete the following questionnaires: COPD Assessment Test [9], Hospital Anxiety and Depression Scale [10], modified Medical Research Council dyspnoea scale [11], St George's Respiratory Questionnaire (SGRQ) [12] and Malnutrition Universal Screening Tool [8]. At the end of the study, the acceptability of the intervention was assessed by a survey (appendix S1 in the supplementary material). A full description of the methodology is presented in appendix S2 in the supplementary material.

\section{Sample size}

The power calculation was conducted using parameters from a previous study [13]. The clinical significance of further increases in ISWT performance resulting from treatment adjunctive to pulmonary rehabilitation is unknown but we judged a priori that an additional increase of $35 \mathrm{~m}$ in the ISWT distance would be of functional benefit. The sample size was calculated to have $90 \%$ power to detect such a difference between treatment arms at the 5\% significance level (Type I error), assuming a standard deviation of $53 \mathrm{~m}$ (obtained from the same study [13]). We assumed a 29\% dropout rate from rehabilitation (using data from a previous study in the same pulmonary rehabilitation class [14]). Therefore, our final desired sample size was 138 COPD patients, with 98 required to complete the study. The minimal clinically important difference (MCID) of the ISWT following pulmonary rehabilitation is now considered to be between 35.0 and $36.1 \mathrm{~m}$ [15], but was $47.5 \mathrm{~m}$ at the time the study was designed [16].

\section{Statistical analysis}

Data were analysed on a modified intention-to-treat basis which included all participants who completed pulmonary rehabilitation and used nutritional supplementation. Data were assessed for normality by visual inspection of histograms and the Kolmogorov-Smirnov test. Baseline characteristics of the intervention and control groups were reported using mean and standard deviation or median and interquartile range as appropriate. For the main outcome of the ISWT, between-group differences were compared by ANCOVA considering baseline ISWT as a covariate. Pre- and post-pulmonary rehabilitation measurements within the intervention and control groups were compared using the paired t-test for normally distributed data and the Wilcoxon signed-rank test for nonnormally distributed data. Independent t-tests were used to compare the mean difference between the two groups for normally distributed data and Mann-Whitney U-tests were used for nonnormally distributed data. Each participant in the intervention group was classified as a responder (improvement of $>36.1 \mathrm{~m}$ in ISWT distance) or a nonresponder and baseline characteristics were compared. SPSS version 26 (IBM, Armonk, NY, USA) was used to analyse data.

\section{Results}

We approached and screened 221 consecutive patients referred to pulmonary rehabilitation between 7 January 2019 and 31 January 2020. The CONSORT diagram is provided as figure 1, and includes patients who were excluded, withdrew and completed the trial. 125 (56.5\%) were ineligible and 28 (12.7\%) declined to consent, resulting in 68 participants (male $n=42$ and female $n=26$ ) randomised to receive FCP (intervention $\mathrm{n}=36$ ) or PreOp (control $\mathrm{n}=32$ ) and who started pulmonary rehabilitation. Of the 68 participants, 44 (intervention $n=22$ and control $n=22$ ) completed 6 weeks of pulmonary rehabilitation 


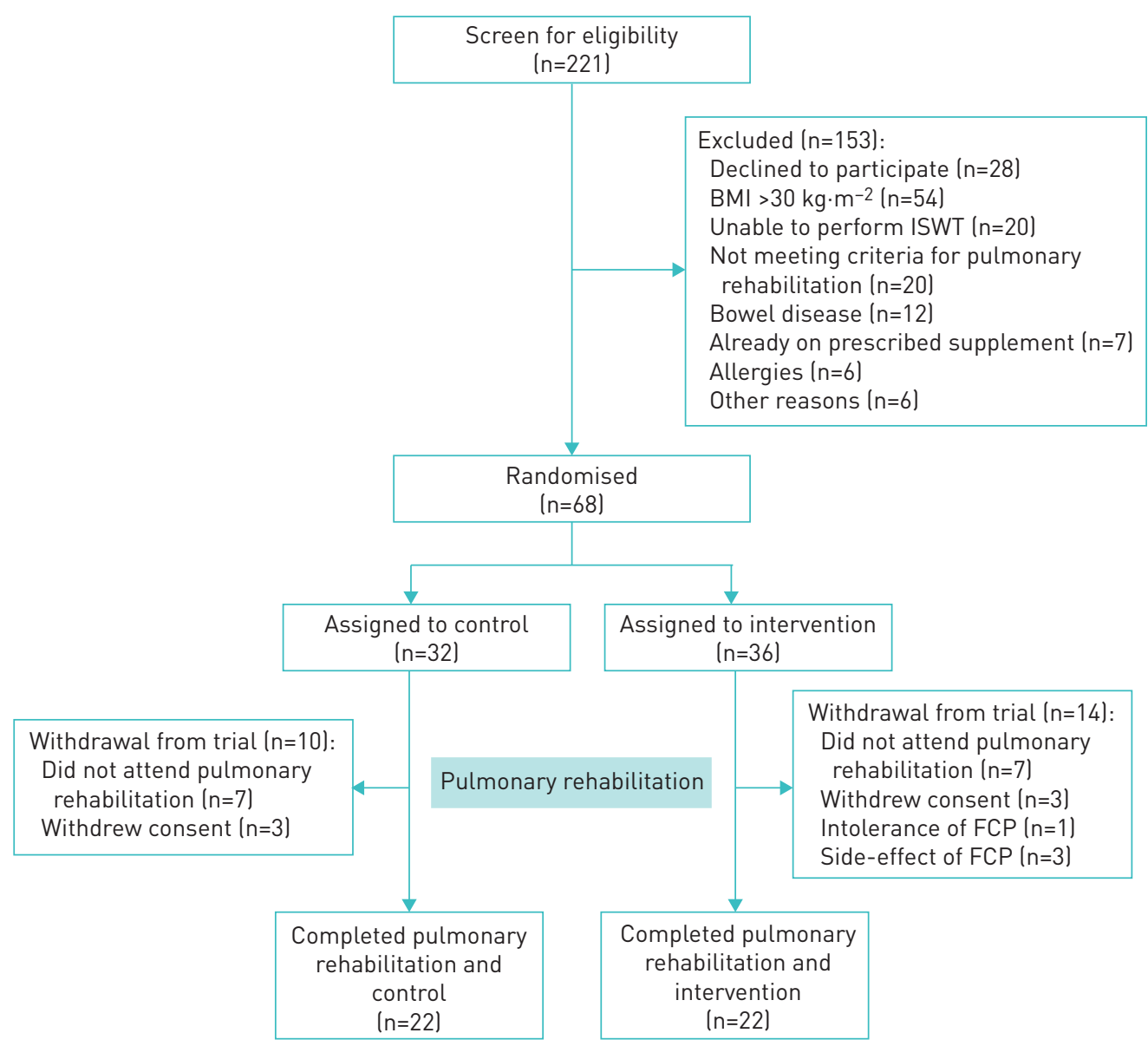

FIGURE 1 CONSORT recruitment diagram for enrolment and study completion. BMI: body mass index; ISWT: incremental shuttle walk test; FCP: Fortisip Compact Protein.

using nutritional supplementation and had both baseline and end of pulmonary rehabilitation measurements available. 14 participants (intervention $n=7$ and control $n=7$ ) withdrew from pulmonary rehabilitation. Four participants in the intervention arm withdrew due to side-effects/intolerance to the FCP supplement. There was no significant difference in dropout rate between the intervention and control groups. The compliance with supplements was calculated from the diary card, and was 96\% (87-100\%) in the control group and $97 \%(90-100 \%)$ in the intervention group. At this point, the trial was stopped due to the COVID-19 pandemic which closed the pulmonary rehabilitation class and analysis was performed.

The baseline characteristics of participants who completed versus those that did not complete pulmonary rehabilitation are presented in appendix S3 in the supplementary material. The baseline characteristics for those completing (control $n=22$ and intervention $n=22$ ) are presented in table 1 . The intervention group was older than the control group (control $70 \pm 9$ years versus intervention $75 \pm 6$ years; $p=0.04$ ). There were fewer ex-smokers in the control group than in the intervention group (control 55\% versus intervention $77 \%)$. A history of hospitalisation in the past year due to COPD exacerbation was significantly higher in the control group (control $0(0-1)$ versus intervention $0(0-0) ; \mathrm{p}=0.03)$. SGRQ total, activity and impact domains showed a significantly higher impact of COPD in the control group compared with the intervention group (SGRQ total score $52 \pm 17$ versus $41 \pm 13$; p $=0.02$; SGRQ activity score 57 (57-86) versus 57 (53-69); $\mathrm{p}=0.03$ and SGRQ impact score $38 \pm 19$ versus $27 \pm 12 ; \mathrm{p}=0.03$ ).

\section{Primary outcome: ISWT}

Both the control and intervention groups experienced a significant improvement in ISWT distance following pulmonary rehabilitation $(40 \pm 60 \mathrm{~m} ; \mathrm{p}=0.005$ and $73 \pm 68 \mathrm{~m} ; \mathrm{p}<0.001$, respectively). After adjusting for baseline ISWT distance, the post-walk distance for the intervention group was $342 \pm 149 \mathrm{~m}$ compared with $305 \pm 148 \mathrm{~m}$ in the control group. This difference did not meet the pre-planned statistical cut-off of $5 \%(\mathrm{p}=0.10$; ANCOVA). However, it did meet the a priori definition of functional benefit in the ISWT of $>35 \mathrm{~m}$. It also exceeds the MCID in the ISWT of $>36.1 \mathrm{~m}$, as the mean difference between arms 


\begin{tabular}{|c|c|c|c|}
\hline & Control & Intervention & p-value \\
\hline Subjects & 22 & 22 & \\
\hline \multicolumn{4}{|l|}{ Demographics } \\
\hline Age years & $70 \pm 9$ & $75 \pm 6$ & $0.04^{*}$ \\
\hline Sex & & & 0.53 \\
\hline Male & 13 (59) & $15(68)$ & \\
\hline Female & $9(41)$ & $7(32)$ & \\
\hline Active smoker & $10(45)$ & $5(23)$ & 0.20 \\
\hline Ex-smoker & 12 (55) & $17(77)$ & \\
\hline Smoking history pack-years & $39(24-59)$ & $45(28-93)$ & 0.41 \\
\hline Exacerbation within last year & $1(0-2)$ & $0(0-1)$ & 0.21 \\
\hline Hospitalisation due to exacerbations within last year & $0(0-1)$ & $0(0-0)$ & $0.03 *$ \\
\hline \multicolumn{4}{|l|}{ Medications } \\
\hline SABA & $15(68)$ & $15(68)$ & 0.81 \\
\hline LABA & $15(68)$ & $9(41)$ & 0.09 \\
\hline SAMA & 0 & 0 & \\
\hline LAMA & $16(73)$ & $8(36)$ & $0.02 *$ \\
\hline ICS & $12(54)$ & $7(32)$ & 0.16 \\
\hline Nonrespiratory medications & $17(77)$ & $20(91)$ & 0.09 \\
\hline Diabetes & 0 & 0 & \\
\hline \multicolumn{4}{|l|}{ Pulmonary function } \\
\hline $\mathrm{FEV}_{1} \mathrm{~L}$ & $1.2(1-2)$ & $1.6(1-2)$ & 0.27 \\
\hline $\mathrm{FEV}_{1} \%$ pred & $52 \pm 19$ & $59 \pm 22$ & 0.18 \\
\hline $\mathrm{FEV}_{1} / \mathrm{FVC} \%$ & $54 \pm 12$ & $53 \pm 13$ & 0.90 \\
\hline \multicolumn{4}{|l|}{ Anthropometric measurements } \\
\hline Weight kg & $68 \pm 13$ & $75 \pm 16$ & 0.12 \\
\hline Waist circumference $\mathrm{cm}$ & $92 \pm 14$ & $96 \pm 15$ & 0.46 \\
\hline Hip circumference $\mathrm{cm}$ & $98 \pm 9$ & $104 \pm 11$ & $0.04^{*}$ \\
\hline Mid-thigh circumference $\mathrm{cm}$ & $56 \pm 8$ & $59 \pm 6$ & 0.16 \\
\hline \multicolumn{4}{|l|}{ Body composition } \\
\hline Fat mass kg & $24 \pm 7$ & $26 \pm 6$ & 0.50 \\
\hline $\mathrm{BMI} \mathrm{kg} \cdot \mathrm{m}^{-2}$ & $23 \pm 4$ & $24 \pm 4$ & 0.36 \\
\hline Fat-free mass $\mathrm{kg}$ & $43 \pm 10$ & $49 \pm 13$ & 0.12 \\
\hline $\mathrm{FFMI} \mathrm{kg} \cdot \mathrm{m}^{-2}$ & $15 \pm 3$ & $16 \pm 3$ & 0.17 \\
\hline \multicolumn{4}{|l|}{ Functional outcomes } \\
\hline ISWT m & $265 \pm 133$ & $269 \pm 130$ & 0.92 \\
\hline mMRC grade & $3(2-3)$ & $3(2-3)$ & 0.87 \\
\hline Right handgrip kg & $26 \pm 19$ & $30 \pm 10$ & 0.15 \\
\hline Left handgrip kg & $25 \pm 9$ & $29 \pm 9$ & 0.16 \\
\hline STS5 s & $11(7-13)$ & $10(9-12)$ & 0.94 \\
\hline \multicolumn{4}{|l|}{ Questionnaires } \\
\hline CAT score & $20 \pm 8$ & $18 \pm 6$ & 0.37 \\
\hline Anxiety (HADS) score & $6(4-9)$ & $4(3-10)$ & 0.42 \\
\hline Depression (HADS) score & $6 \pm 3$ & $5 \pm 3$ & 0.19 \\
\hline SGRQ total score & $52 \pm 17$ & $41 \pm 13$ & $0.02 *$ \\
\hline SGRQ symptoms score & $63 \pm 23$ & $52 \pm 21$ & 0.14 \\
\hline SGRQ activity score & $57(57-86)$ & $57(53-69)$ & $0.03^{*}$ \\
\hline SGRQ impact score & $38 \pm 19$ & $27 \pm 12$ & $0.03^{*}$ \\
\hline MUST score & $0(0-1)$ & $0(0-0)$ & 0.50 \\
\hline Physical activity steps-day ${ }^{-1}$ & 2663 (1947-4912) & $4297(1726-7211)$ & 0.33 \\
\hline
\end{tabular}

Data are presented as $\mathrm{n}$, mean $\pm \mathrm{SD}, \mathrm{n}(\%)$ or median (interquartile range), unless otherwise stated. SABA: short-acting $\beta$-agonist; LABA: long-acting $\beta$-agonist; SAMA: short-acting muscarinic antagonist; LAMA: long-acting muscarinic antagonist; ICS: inhaled corticosteroid; $F_{E V}$ : forced expiratory volume in $1 \mathrm{~s} ; \mathrm{FVC}$ : forced vital capacity; BMI: body mass index; FFMI: fat-free mass index; ISWT: incremental shuttle walk test; mMRC: modified Medical Research Council; STS5: five-repetition sit-to-stand test; CAT: COPD Assessment Test; HADS: Hospital Anxiety and Depression Scale; SGRQ: St George's Respiratory Questionnaire; MUST: Malnutrition Universal Screening Tool. \#: p-values were calculated using the Chi-squared, paired t-test for normally distributed data and the Wilcoxon signed-rank test for nonnormally distributed data, and represent a comparison between the control and intervention groups. ${ }^{*}: p<0.05$. 
was $37 \mathrm{~m}$. The variability between participants in the control and intervention groups (148 and $149 \mathrm{~m}$, respectively) was considerably higher than that found in previous studies. This difference in the ISWT is illustrated in figure 2 .

\section{Secondary outcomes}

The within- and between-group changes in functional, anthropometric, body composition and HRQoL measures following pulmonary rehabilitation are reported in table 2. Within the control group, there were significant improvements after pulmonary rehabilitation in right handgrip $(3 \pm 4 \mathrm{~kg} ; \mathrm{p}<0.05)$, left handgrip $(3 \pm 5 \mathrm{~kg} ; \mathrm{p}<0.05)$, STS5 time $(-3(-5--1) \mathrm{s}) ; \mathrm{p}<0.01)$, body weight $(1 \pm 2 \mathrm{~kg} ; \mathrm{p}<0.05)$ and mid-thigh circumference $(2 \pm 4 \mathrm{~cm} ; \mathrm{p}<0.05)$.

Within the intervention group, there were significant improvements after pulmonary rehabilitation in right handgrip $(2 \pm 3 \mathrm{~kg} ; \mathrm{p}<0.05)$, left handgrip $(2 \pm 3 \mathrm{~kg} ; \mathrm{p}<0.01)$, STS5 time $(-2(-2--1 \mathrm{~s}) ; \mathrm{p}<0.01)$, body weight $(1 \pm 2 \mathrm{~kg} ; \mathrm{p}<0.01)$ and mid-thigh circumference $(1 \pm 3 \mathrm{~cm} ; \mathrm{p}<0.05)$. There were no significant differences between the intervention and control groups.

Participants taking the intervention supplement were divided into those who responded on the ISWT and those who did not respond. The baseline characteristics of responders and nonresponders are presented in table 3 .

There were significant differences in baseline mid-thigh circumference (responders $62 \pm 4 \mathrm{~cm}$ versus nonresponders $55 \pm 6 \mathrm{~cm} ; \mathrm{p}=0.006$ ) favouring the responder group and higher baseline depression scores (responders $7 \pm 4$ versus nonresponders $3 \pm 2 ; \mathrm{p}<0.04$ ), although the latter were both clinically within the normal range and this difference is higher than the MCID of 1.4 points.

There were no significant differences between baseline characteristics between responders and nonresponders in the control group.

\section{Patient experience}

$79 \%$ of participants were satisfied with the taste of the supplement. $43 \%$ of the participants in the intervention (FCP) group wished to continue taking the product and 57\% did not due to flavour, sweetness, texture or inconvenience.

Three participants in the intervention group developed mild diarrhoea, all of whom discontinued the supplement. No other side-effects were reported.

\section{Discussion}

This study investigated the effect of high-protein supplementation during pulmonary rehabilitation in COPD. We show that in COPD patients enrolled in a 6-week pulmonary rehabilitation programme, high-protein nutritional supplementation was not associated with a statistically significant improvement in exercise capacity measured by the ISWT above that seen due to pulmonary rehabilitation alone. However, there was a clinically meaningful difference favouring the intervention group.

Our study was stopped because of the coronavirus pandemic and we therefore present this study as a pilot trial. Our results suggest that using a high-protein supplement might enhance exercise capacity gains during pulmonary rehabilitation, but that further research would be required to confirm this. Our data are in keeping with other randomised controlled trials that have examined diverse nutritional supplements, including creatine, high-carbohydrate and protein supplements [13, 17-20]. Our participants were very

FIGURE 2 Post-pulmonary rehabilitation incremental shuttle walk test (ISWT) distance in the control $(305 \pm 148 \mathrm{~m})$ and intervention groups $(342 \pm 149 \mathrm{~m})(\mathrm{p}=0.10)$. Data are presented as mean and standard deviation.

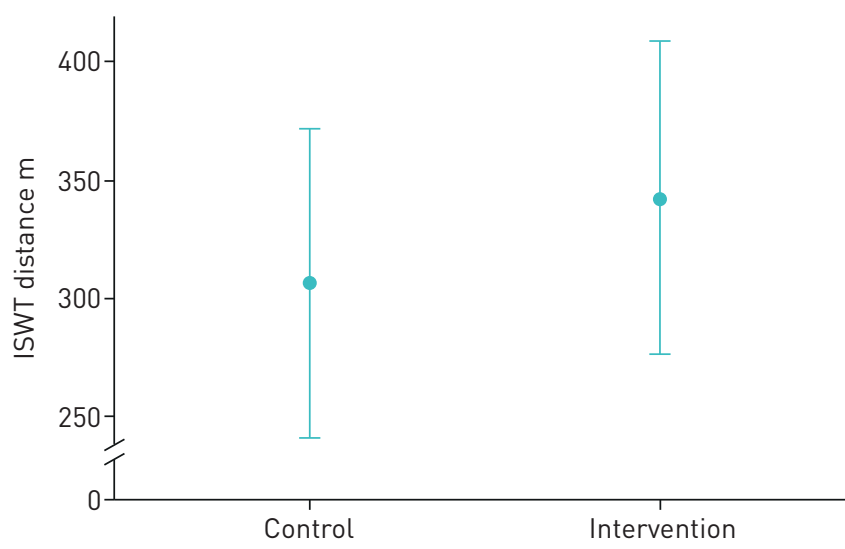




\begin{tabular}{|c|c|c|c|c|c|c|c|c|}
\hline & \multicolumn{2}{|c|}{ Control } & \multicolumn{2}{|c|}{ Intervention } & $\begin{array}{l}\text { Between-group } \\
\text { difference }\end{array}$ & $95 \% \mathrm{Cl}$ & $\begin{array}{l}\text { Effect } \\
\text { size }\end{array}$ & p-value ${ }^{+}$ \\
\hline \multicolumn{9}{|l|}{ Functional outcomes } \\
\hline ISWT m & $265 \pm 133$ & $305 \pm 148$ & $269 \pm 129$ & $342 \pm 149$ & $32 \pm 85$ & $-5-70$ & 2.7 & 0.10 \\
\hline Left handgrip kg & $25 \pm 9$ & $28 \pm 10$ & $29 \pm 9$ & $30 \pm 10$ & $0.9 \pm 7$ & $-2-4$ & 0.5 & 0.33 \\
\hline STS5 s & $10(7-13)$ & $8(6-10)$ & $11(9-12)$ & $9(7-12)$ & $-1(-4-0.3)$ & $-5-0.2$ & 4 & 0.08 \\
\hline \multicolumn{9}{|l|}{ Anthropometric measurements } \\
\hline Weight kg & $68 \pm 13$ & $69 \pm 13$ & $75 \pm 16$ & $76 \pm 16$ & $0.4 \pm 2$ & $-0.6-2$ & 0.2 & 0.50 \\
\hline Waist circumference $\mathrm{cm}$ & 94 (78-105) & $94(77-102)$ & $93(87-105)$ & $96(85-111)$ & $1(-3-1)$ & $1-3$ & 0.1 & 0.38 \\
\hline Hip circumference $\mathrm{cm}$ & $98 \pm 9$ & $98 \pm 9$ & $104 \pm 11$ & $103 \pm 9$ & $2 \pm 6$ & $-1-4$ & 1.2 & 0.11 \\
\hline FFMI $\mathrm{kg} \cdot \mathrm{m}^{-2}$ & $15 \pm 3$ & $15 \pm 3$ & $16 \pm 3$ & $17 \pm 4$ & $0.1 \pm 2$ & $-1-1$ & 0.001 & 0.38 \\
\hline \multicolumn{9}{|l|}{ Questionnaires } \\
\hline CAT score & $20 \pm 8$ & $19 \pm 8$ & $18 \pm 6$ & $17 \pm 7$ & $0.04 \pm 8$ & $-3-3$ & 0.12 & 0.98 \\
\hline Anxiety (HADS) score & $7 \pm 4$ & $6 \pm 5$ & $6 \pm 5$ & $5 \pm 5$ & $0.4 \pm 3$ & $-1-2$ & 1 & 0.55 \\
\hline Depression (HADS) score & $6 \pm 3$ & $6 \pm 3$ & $5 \pm 3$ & $4 \pm 4$ & $0.5 \pm 3$ & $-1-2$ & 0.03 & 0.39 \\
\hline SGRQ total score & $52 \pm 17$ & $51 \pm 17$ & $41 \pm 13$ & $43 \pm 16$ & $2 \pm 15$ & $-5-10$ & 0.006 & 0.48 \\
\hline SGRQ symptoms score & $63 \pm 23$ & $57 \pm 20$ & $52 \pm 21$ & $49 \pm 27$ & $3 \pm 28$ & $-11-17$ & 0.06 & 0.76 \\
\hline SGRQ activity score & $72 \pm 18$ & $71 \pm 19$ & $60 \pm 17$ & $66 \pm 21$ & $6 \pm 21$ & $-5-16$ & 0.5 & 0.20 \\
\hline SGRQ impact score & $38 \pm 19$ & $36.6 \pm 20$ & $27 \pm 12$ & $28 \pm 16$ & $0.5 \pm 18$ & $-9-10$ & 0.001 & 0.74 \\
\hline MUST score & $0(0-1)$ & $0(0-1)$ & $0(0-0)$ & $0(0-0)$ & $0(0-0)$ & 0 & & 1 \\
\hline Physical activity steps $\cdot$ day $^{-1}$ & $\begin{array}{c}2663 \\
(1947-4912)\end{array}$ & $\begin{array}{c}2903 \\
(1800-4753)\end{array}$ & $\begin{array}{c}4297 \\
(1726-7211)\end{array}$ & $\begin{array}{c}5973 \\
(2000-6812)\end{array}$ & $\begin{array}{c}31 \\
(-1421-1337)\end{array}$ & $-974-1369$ & 0.04 & 0.88 \\
\hline
\end{tabular}

Data are presented as mean \pm SD or median (interquartile range), unless otherwise stated. ISWT: incremental shuttle walk test; mMRC: modified Medical Research Council; STS5: five-repetition sit-to-stand test; FFMI: fat-free mass index; CAT: COPD Assessment Test; COPD: chronic obstructive pulmonary disease; HADS: Hospital Anxiety and Depression Scale; SGRQ: St George's Respiratory Questionnaire; MUST: Malnutrition Universal Screening Tool. " : control $n=22$ and intervention $n=22 ;{ }^{~}$ : mean difference for each group was calculated by subtracting baseline from post-rehabilitation measurements; ${ }^{+}:$-values were calculated using the paired t-test for normally distributed data and the Wilcoxon signed-rank test for nonnormally distributed data, and represent the change between the mean differences in the control and intervention groups.

heterogeneous with variation in exercise capacity measured by the ISWT. This likely reflects variation in lower extremity strength, muscle weakness, baseline exercise tolerance and ventilatory limitation.

We found there was an improvement in handgrip strength noted in association with pulmonary rehabilitation, but no additional effect of protein supplementation, suggesting that supplementation may have different effects on different muscle groups. This is similar to results in previous studies [13, 21, 22]. For example, using carnitine for 8 weeks during pulmonary rehabilitation did not significantly improve handgrip strength when compared with a control group who received glucose [21].

The STS5 exercise assesses daily activities that rely on lower limb muscle performance. In COPD, STS5 correlates with HRQoL and lower limb strength [23]. We were unable to show a significant difference between groups, although there were significant improvements within each group in response to pulmonary rehabilitation, as would be expected in an effective pulmonary rehabilitation programme. In COPD patients who underwent outpatient pulmonary rehabilitation, STS5 was responsive and significantly correlated with exercise capacity [24].

Our data demonstrate that participants who received the intervention and reached or exceeded $36 \mathrm{~m}$ (MCID) in the ISWT had a larger mid-thigh circumference at baseline. Similar associations were reported in a study in which mid-thigh circumference was positively associated with exercise capacity in COPD [25]. Additionally, thigh muscle strength (e.g. quadriceps) has been positively associated with exercise capacity [26]. As muscle mass increased, strength and endurance improved [26]. This suggests that those who responded to the intervention might initially have higher muscle mass, especially in the lower limbs. We did not find any differences between the groups in hip or waist circumference. 


\begin{tabular}{|c|c|c|c|}
\hline & Responders & Nonresponders & p-value \\
\hline Subjects & 13 & 9 & \\
\hline \multicolumn{4}{|l|}{ Demographics } \\
\hline Age years & $74 \pm 5$ & $78 \pm 6$ & 0.15 \\
\hline Sex & & & 0.90 \\
\hline Male & $9(69)$ & $6(66)$ & \\
\hline Female & $4(31)$ & $3(33)$ & \\
\hline Ex-smoker & $10(77)$ & 7 (78) & 0.96 \\
\hline Smoking history pack-years & $49(28-105)$ & $45(21-49)$ & 0.34 \\
\hline Exacerbation within last year & 5 (38) & $5(56)$ & 0.43 \\
\hline Hospitalisation due to exacerbations within last year & $0(0)$ & $1(11)$ & 0.22 \\
\hline \multicolumn{4}{|l|}{ Anthropometric measurements } \\
\hline Weight kg & $78 \pm 14$ & $71 \pm 18$ & 0.32 \\
\hline Waist circumference $\mathrm{cm}$ & $98 \pm 12$ & $92 \pm 18$ & 0.33 \\
\hline Hip circumference $\mathrm{cm}$ & $106 \pm 8$ & $102 \pm 15$ & 0.44 \\
\hline Mid-thigh circumference $\mathrm{cm}$ & $62 \pm 4$ & $55 \pm 6$ & $0.006 *$ \\
\hline \multicolumn{4}{|l|}{ Pulmonary function } \\
\hline $\mathrm{FEV}_{1} \%$ pred & $59 \pm 22$ & $52 \pm 19$ & 0.28 \\
\hline $\mathrm{FEV}_{1} / \mathrm{FVC} \%$ & $53 \pm 13$ & $54 \pm 12$ & 0.75 \\
\hline \multicolumn{4}{|l|}{ Body composition } \\
\hline $\mathrm{BMI} \mathrm{kg} \cdot \mathrm{m}^{-2}$ & $25 \pm 3$ & $24 \pm 5$ & 0.50 \\
\hline Fat-free mass kg & $16 \pm 2$ & $15 \pm 3$ & 0.29 \\
\hline $\mathrm{FFMI} \mathrm{kg} \cdot \mathrm{m}^{-2}$ & $52 \pm 13$ & $45 \pm 14$ & 0.38 \\
\hline \multicolumn{4}{|l|}{ Functional outcomes } \\
\hline ISWT m & $265 \pm 134$ & $274 \pm 132$ & 0.88 \\
\hline mMRC grade & $3(2-3)$ & $3(2-3)$ & 0.95 \\
\hline Right handgrip kg & $32 \pm 12$ & $28 \pm 8$ & 0.45 \\
\hline Left handgrip kg & $30 \pm 10$ & $27 \pm 8$ & 0.43 \\
\hline STS5 s & $11 \pm 3$ & $11 \pm 4$ & 0.89 \\
\hline \multicolumn{4}{|l|}{ Questionnaires } \\
\hline CAT score & $19 \pm 6$ & $18 \pm 7$ & 0.78 \\
\hline Anxiety (HADS) score & $6(2-13)$ & $3(2-7)$ & 0.26 \\
\hline Depression (HADS) score & $7 \pm 4$ & $3 \pm 2$ & $0.04^{*}$ \\
\hline SGRQ total score & $42 \pm 14$ & $39 \pm 12$ & 0.56 \\
\hline MUST score & $0(0-0)$ & $0(0-2)$ & 0.36 \\
\hline Physical activity steps-day ${ }^{-1}$ & $4909 \pm 2851$ & $3930 \pm 3495$ & 0.49 \\
\hline \multicolumn{4}{|c|}{$\begin{array}{l}\text { Data are presented as } n, \text { mean } \pm \text { SD, } n(\%) \text { or median linterquartile range), unless otherwise stated. FEV }{ }_{1} \text { : } \\
\text { forced expiratory volume in } 1 \mathrm{~s} \text {; FVC: forced vital capacity; BMI: body mass index; FFMI: fat-free mass } \\
\text { index; mMRC: modified Medical Research Council dyspnoea scale; STS5: five-repetition sit-to-stand test; } \\
\text { CAT: COPD Assessment Test; COPD: chronic obstructive pulmonary disease; HADS: Hospital Anxiety and } \\
\text { Depression Scale; SGRQ: St George's Respiratory Questionnaire; MUST: Malnutrition Universal Screening } \\
\text { Tool. *: p<0.05. }\end{array}$} \\
\hline
\end{tabular}

We found that participants who exceeded the MCID in the ISWT with the supplement had a higher baseline depression score (although still within the normal range) and this was higher than in the nonresponder group by more than the MCID of 1.4 points [27]. In COPD patients, depression has a negative impact on pulmonary rehabilitation outcomes such as exercise capacity and dyspnoea which might unfavourably affect the distance walked in the ISWT during the baseline visit [28]. Our pulmonary rehabilitation programme involved exercise and education, including stress management. Treating depression might positively impact exercise capacity, allowing further improvement at the end of pulmonary rehabilitation.

We were required to stop recruitment due to the COVID-19 pandemic; consequently 44 subjects completed the study. Pulmonary rehabilitation in London was eventually transferred to an online service, preventing continuation of the study, and at this point we analysed our data. Our data can be used to inform the power calculation of a definitive study. The ISWT distances in the control and intervention groups after our pulmonary rehabilitation programme were $40 \pm 60$ and $73 \pm 68 \mathrm{~m}$, respectively. The dropout rate was $35 \%$. A sample size calculation with $80 \%$ power at $5 \%$ significance level and standard deviation of $65 \mathrm{~m}$ (the average standard deviation of the ISWT distance for both groups) with $35 \%$ dropout suggests a study would need to recruit 190 COPD patients (95 per group), with 124 completing the study. 


\section{Limitations}

We failed to recruit the required sample size because we were forced to stop the trial early. As such, we present this as a pilot trial. Additionally, the strict criteria for inclusion (e.g. BMI $<30 \mathrm{~kg} \cdot \mathrm{m}^{-2}$ ) limited recruitment. We did not assess muscle mass (e.g. with ultrasound) or measure quadriceps strength. This might more accurately quantify the effect of the intervention on lower limb muscles. Thigh circumference may not be the most accurate measurement, especially in obese patients. There were some differences between groups in baseline characteristics such as age, number of hospital admission and QoL which may have impacted outcomes. We could not provide a placebo identical to the intervention, but were able to relabel both products, and both the assessor and the patients were blind to this. There was heterogeneity in the exercise capacity measured by the ISWT between participants. We observed a larger standard deviation for the 6-week ISWT than expected. We were not able to collect empty bottles to verify compliance with the supplement, relying only on the diary card.

\section{Conclusions}

Using a high-protein nutritional supplementation in COPD patients who were enrolled in pulmonary rehabilitation, we were not able to identify a statistically significant difference between the intervention and control groups in exercise capacity measured by the ISWT or in other secondary outcomes, which is likely due to the small sample size. However, there was a clinically meaningful difference favouring the intervention and the individuals who reached that improvement had a larger mid-thigh circumference at baseline. Nutritional supplements were acceptable to patients. Further definitive research investigating the potential utility of nutritional supplements in this population is warranted.

Author contributions: The study was designed by A.M. Aldhahir, J.R. Hurst and S. Mandal. Data collection was led by A.M. Aldhahir with assistance from Y.S. Aldabayan and J.S. Alqahtani. A.M. Aldhahir led the data analysis, supervised by C. Smith. A.M. Aldhahir wrote the first draft of the manuscript. All authors revised the manuscript for important intellectual content and approved the final version for submission.

Conflict of interest: A.M. Aldhahir has nothing to disclose. Y.S. Aldabayan has nothing to disclose. J.S. Alqahtani has nothing to disclose. H.A. Ridsdale has nothing to disclose. C. Smith reports personal fees for educational materials from Gilead and grants from ViiV Healthcare outside the submitted work. J.R. Hurst reports support to attend meetings, and payment for educational and advisory work, personally, and University College London received payment for educational activity and advisory work from pharmaceutical companies that make medicines to treat COPD, outside the submitted work. S. Mandal has nothing to disclose.

Support statement: This trial was conducted as part of a $\mathrm{PhD}$ funded in association with Jazan University (Jazan, Saudi Arabia) through the Saudi Arabian Cultural Bureau (London, UK). Intervention and control supplements were generously provided by Nutricia (Zoetermeer, The Netherlands), the manufacturer, who otherwise had no role in the conduct or analysis of the research. Funding information for this article has been deposited with the Crossref Funder Registry.

\section{References}

1 Janson C, Marks G, Buist S, et al. The impact of COPD on health status: findings from the BOLD study. Eur Respir J 2013; 42: 1472-1483.

2 Van Remoortel H, Hornikx M, Demeyer H, et al. Daily physical activity in subjects with newly diagnosed COPD. Thorax 2013; 68: 962-963.

3 Majid H, Kanbar-Agha F, Sharafkhaneh A. COPD: osteoporosis and sarcopenia. COPD Res Practice 2016; 2: 3.

4 Engelen MP, Schols AM, Does JD, et al. Skeletal muscle weakness is associated with wasting of extremity fat-free mass but not with airflow obstruction in patients with chronic obstructive pulmonary disease. Am J Clin Nutr 2000; 71: 733-738.

5 McCarthy B, Casey D, Devane D, et al. Pulmonary rehabilitation for chronic obstructive pulmonary disease. Cochrane Database Syst Rev 2015; 2: 1-209.

6 Nici L, Donner C, Wouters E, et al. American Thoracic Society/European Respiratory Society statement on pulmonary rehabilitation. Am J Respir Crit Care Med 2006; 173: 1390-1413.

7 Aldhahir AM, Rajeh AMA, Aldabayan YS, et al. Nutritional supplementation during pulmonary rehabilitation in COPD: a systematic review. Chron Respir Dis 2020; 17: 1479973120904953.

8 Anderson L, Banner J, Bostock B, et al. Managing Malnutrition in COPD. Malnutrition Pathway. 2020. www. malnutritionpathway.co.uk/copd Date last accessed: 19 February 2021.

9 Dodd JW, Hogg L, Nolan J, et al. The COPD assessment test (CAT): response to pulmonary rehabilitation. A multicentre, prospective study. Thorax 2011; 66: 425-429.

10 Stern AF. The Hospital Anxiety and Depression Scale. Occup Med 2014; 64: 393-394.

11 Bestall JC, Paul EA, Garrod R, et al. Usefulness of the Medical Research Council (MRC) dyspnoea scale as a measure of disability in patients with chronic obstructive pulmonary disease. Thorax 1999; 54: 581-586.

12 Jones PW, Quirk FH, Baveystock CM. The St George's Respiratory Questionnaire. Respir Med 1991; 85: Suppl. B, $25-31$.

13 Steiner MC, Barton RL, Singh SJ, et al. Nutritional enhancement of exercise performance in chronic obstructive pulmonary disease: a randomised controlled trial. Thorax 2003; 58: 745-751.

14 Aldabayan YS, Ridsdale HA, Alrajeh AM, et al. Pulmonary rehabilitation, physical activity and aortic stiffness in COPD. Respir Res 2019; 20: 166. 
15 Evans RA, Singh SJ. Minimum important difference of the incremental shuttle walk test distance in patients with COPD. Thorax 2019; 74: 994-995.

16 Holland AE, Spruit MA, Troosters T, et al. An official European Respiratory Society/American Thoracic Society technical standard: field walking tests in chronic respiratory disease. Eur Respir J 2014; 44: 1428-1446.

17 Gurgun A, Deniz S, Argin M, et al. Effects of nutritional supplementation combined with conventional pulmonary rehabilitation in muscle-wasted chronic obstructive pulmonary disease: a prospective, randomized and controlled study. Respirology 2013; 18: 495-500.

18 Deacon SJ, Vincent EE, Greenhaff PL, et al. Randomized controlled trial of dietary creatine as an adjunct therapy to physical training in chronic obstructive pulmonary disease. Am J Respir Crit Care Med 2008; 178: 233-239.

19 Fuld JP, Kilduff LP, Neder JA, et al. Creatine supplementation during pulmonary rehabilitation in chronic obstructive pulmonary disease. Thorax 2005; 60: 531-537.

20 Laviolette L, Lands LC, Dauletbaev N, et al. Combined effect of dietary supplementation with pressurized whey and exercise training in chronic obstructive pulmonary disease: a randomized, controlled, double-blind pilot study. J Med Food 2010; 13: 589-598.

21 Faager G, Soderlund K, Skold CM, et al. Creatine supplementation and physical training in patients with COPD: a double blind, placebo-controlled study. Int J Chronic Obstr Pulm Dis 2006; 1: 445-453.

22 Broekhuizen R, Wouters EF, Creutzberg EC, et al. Polyunsaturated fatty acids improve exercise capacity in chronic obstructive pulmonary disease. Thorax 2005; 60: 376-382.

23 Zhang Q, Li Y-X, Li X-L, et al. A comparative study of the five-repetition sit-to-stand test and the 30-second sit-to-stand test to assess exercise tolerance in COPD patients. Int J Chron Obstruct Pulmon Dis 2018; 13: 2833-2839.

24 Jones SE, Kon SS, Canavan JL, et al. The five-repetition sit-to-stand test as a functional outcome measure in COPD. Thorax 2013; 68: 1015-1020.

25 Hallin R, Janson C, Arnardottir RH, et al. Relation between physical capacity, nutritional status and systemic inflammation in COPD. Clin Respir J 2011; 5: 136-142.

26 Hamilton AL, Killian KJ, Summers E, et al. Muscle strength, symptom intensity, and exercise capacity in patients with cardiorespiratory disorders. Am J Respir Crit Care Med 1995; 152: 2021-2031.

27 Puhan MA, Frey M, Büchi S, et al. The minimal important difference of the Hospital Anxiety and Depression Scale in patients with chronic obstructive pulmonary disease. Health Quality Life Outcomes 2008; 6: 46.

28 von Leupoldt A, Taube K, Lehmann K, et al. The impact of anxiety and depression on outcomes of pulmonary rehabilitation in patients with COPD. Chest 2011; 140: 730-736. 